Article

\title{
Ferromagnetic Resonance Spectroscopy and Rock Magnetic Characterization of Fossil Coral Skeletons in Ishigaki Islands, Japan
}

\author{
Yuho Kumagai ${ }^{1, * \mathbb{C}}$, Norihiro Nakamura ${ }^{2}$, Tetsuro Sato $^{3}$, Toshitaka Oka $^{2}$ and Hirokuni Oda ${ }^{3}$ \\ 1 Department of Earth Science, Tohoku University, 6-3, Aramaki-aza-Aoba, Aoba-ku, Sendai, \\ Miyagi 980-8578, Japan \\ 2 Institute for Excellence in Higher Education, Tohoku University, 41, Kawauchi, Aoba-ku, Sendai, \\ Miyagi 980-8576, Japan; n-naka@tohoku.ac.jp (N.N.); kotobuki@m.tohoku.ac.jp (T.O.) \\ 3 Geological Survey of Japan, National Institute of Advanced Industrial Science and Technology, \\ Tsukuba central 7, 1-1-1, Higashi, Tsukuba, Ibaraki 305-8567, Japan; tetsuro-satou@aist.go.jp (T.S.); \\ hirokuni-oda@aist.go.jp (H.O.) \\ * Correspondence: tobihane55@gmail.com; Tel.: +81-227-953-397
}

Received: 9 October 2018; Accepted: 31 October 2018; Published: 2 November 2018

\begin{abstract}
Skeletons of hermatypic corals (e.g., Porites) might have enormous potential as a high-resolution paleomagnetic recorder owing to their rapid and continuous growth over hundreds of years at a rate of up to $2 \mathrm{~cm} /$ year, although typical corals show an extremely weak intensity of remanence and low stability. We found that coral tsunami boulders with negligible amounts of calcite on Ishigaki Island show a measurable intensity of remanence; thus, we attempted to characterize the magnetic assemblages in this coral skeleton to determine whether it is of biogenic or detrital magnetite using first-order reversal curve (FORC) measurements, ferromagnetic resonance (FMR) spectroscopy, and petrological observations through field-emission type scanning electron microscope (FE-SEM) with an acid treatment. The FMR derivative spectra of coral skeleton samples represent multiple derivative maxima and extended low-field absorption, indicating the presence of intact biogenic magnetite chains. FORC diagrams represent a "central ridge" signature with a vertical spread. These FMR and FORC features indicate the magnetization of these coral skeletons that are mainly created using intact biogenic magnetites and mixtures of grains from collapsed biogenic magnetites, pseudo-single domain grains, and multi-domain grains such as detrital magnetite. FE-SEM observations confirm the presence of a chain-like structure of iron oxides corresponding to the features of biogenic magnetite. Therefore, the magnetic mineral assemblage in coralline boulders from Ishigaki Island consists of dominant biogenic-origin single-domain magnetite and a trace amount of detrital component, indicating that fossil coral skeletons in Ishigaki Island have potential for utilization in paleomagnetic studies.
\end{abstract}

Keywords: ferromagnetic resonance; rock magnetism; coral skeletons; biogenic magnetite

\section{Introduction}

Coral skeletons, mainly composed of aragonite, have been used for the reconstruction of past sea-level and paleoclimate in the tropics. In particular, the annual banded skeletons of Porites grow over hundreds of years at a high growth rate of $11-20 \mathrm{~mm} /$ year [1]. Therefore, the remanent magnetization of coral has been an attractive topic because corals have enormous potential for high-resolution paleomagnetic records of pre-observatory times. However, most coral skeletons have shown extremely weak magnetization, and their magnetic origin is not well understood. Sato et al. (2014) [2] succeeded in measuring sufficient magnetization of ceased coral tsunamigenic boulders washed up on the beach 
of Ishigaki Island, despite using a conventional fluxgate spinner magnetometer with a sensitivity of $5 \times 10^{-9} \mathrm{Am}^{2}$. Although many studies on the rock magnetism of shallow-water carbonates have been conducted, recently ceased coral skeletons are a fairly new material applied to rock magnetism. It is necessary to determine the characterization of magnetic assemblages in these coral skeletons to utilize them as new paleomagnetic recorders because paleomagnetic records are affected not only by past geomagnetic field variations but also by the lithologic factors of the samples, such as the mineralogy, grain size, and concentration of the magnetic phases [3].

According to previous rock-magnetic studies carried out on late Cenozoic shallow-water carbonate platforms, two different sources of magnetic mineral assemblages have been reported: biogenic magnetite (magnetosome) and detrital titanomagnetite, which are the main components of remanence carriers in the Bahamas [4] and Tahiti [5], respectively. In the case of samples located under rare terrigenous influx conditions, such as pelagic marine carbonates, reef platforms, and red clay, magnetosome can contribute to paleomagnetic records as stable single-domain magnetic carriers, e.g., [4,6,7]. In Japan, Sakai and Jige (2006) [8] carried out the characterization of magnetic particles in Holocene and Pleistocene shallow-water carbonates in the Ryukyu Islands, determining the presence of fine-grained, single-domain magnetite/maghemite. Based on transmission electron microscope (TEM) observations, they concluded that very short lengths $(40-140 \mathrm{~nm})$ and characteristic morphological features (elongate chains, multi-grain clusters) of magnetite crystals are compatible with magnetite chains formed by magnetotactic bacteria.

Identification of magnetosomes in geological samples has been conducted using micro- and macro-analyses, such as electron microscopy, first-order reversal curve (FORC) diagrams, and ferromagnetic resonance (FMR) spectra, which have been suggested to be effective methods for the detection of magnetosomes, e.g., $[9,10]$. The distinctive characteristics of biogenic magnetite, for instance, a stable single-domain size, narrow shape distribution, and chain-like structure, enable the detection of magnetosomes in geological materials through the combined use of electron microscopy and magnetic methods. FORC diagrams, e.g., [11-13], have been widely used to characterize the magnetic particles in natural samples such as lake or sea sediment, e.g., [14-16]. Such diagrams provide information on the statistical distribution of coercivities and magnetostatic interaction fields for magnetic particles within a sample. Egli et al. (2010) [13] showed that FORC diagrams of environmental samples with abundant magnetosomes are characterized by a central ridge feature, indicating no or negligible magnetostatic interaction $[12,13,15]$. This is because intact magnetosome chains in matrixes act like a well-dispersed uniaxial stable single-domain magnetic grain [17-19].

Ferromagnetic resonance (FMR) spectroscopy has been used as a detector of the magnetic anisotropy effects derived from the mineralogy, composition, and crystal shape. Magnetic grains formed by magnetotactic bacteria are encapsulated in membranes and organized into chains. Because these magnetic grains in magnetosome chains are separated by only a few nanometers, each magnetosome should represent magnetic anisotropy like a single, elongated single-domain magnetic particle. Weiss et al. (2004) [20] first showed that intact magnetotactic bacteria and well-dispersed intact chains of fossilized biogenic magnetite cause a distinguishable FMR spectrum, resulting primarily from the magnetic anisotropy of the magnetosomes, which can be readily distinguished in natural samples. Charilaou et al. (2011) [21] presented a numerical simulation of the FMR spectra of randomly oriented magnetosome assemblies, which takes into account the magnetocrystalline and shape anisotropy field, and displayed very good correspondence with measured spectra of intact cells of magnetotactic bacteria. They modeled the linear particle chains of magnetosome as a prolate ellipsoid, which has its long axis parallel to the Miller index [111] crystallographic direction, the same as that of magnetosome. The magnetostatic interactions between the particles in the linear chain occur in a uniaxial shape anisotropy. Weiss et al. (2004) [20] and Kopp et al. (2006) [22] determined that intact magnetosome chains yield characteristic FMR spectra with secondary or multiple low-field absorption peaks and low-field extended asymmetry on the derivative spectra. They also reported that 
the FMR parameters of magnetosome-bearing samples are $g_{\text {eff }}<2.12, A<1, \alpha<0.30$. They indicated that these traits are caused by the uniaxial-like anisotropy of the magnetosome chains [21].

Although many magnetic techniques for magnetofossil detection have been developed, electron microscopic observations remain a powerful tool for detecting the distinctive morphology of magnetosomes. In the case of carbonate samples, such as pelagic limestones and stalagmites, the dissolving processes of a carbonate matrix are often conducted before a microscopic procedure used to concentrate the magnetic minerals. Freeman (1986) [23] dissolved milled limestone rock samples with a buffered ( $\mathrm{pH} 4)$ acetic acid solution, which does not alter the iron oxide or iron oxyhydroxide. This suggestion was applied to speleothems by Perkins (1996) [24] to prepare samples for electron microscopy of the magnetic grains. Chang et al. (2014) [10] conducted FMR and FORC analyses with the assistance of TEM observations on various types of sediments, and compared their advantages and limitations. They concluded that a combination of FMR and FORC measurements is efficient for the discrimination of many types of samples, although some inorganic materials can have FMR characteristics and a FORC central ridge similar to those of intact magnetosomes.

In this study, we characterized the magnetic mineral assemblages of corals in Ishigaki Island using FMR spectroscopy, FORC measurements, and petrologic observations with a field-emission type scanning electron microscope (FE-SEM) to reveal why the corals in Ishigaki possess such measurable magnetic remanence. Owing to its low NRM intensities and low concentration of magnetic minerals, acid treatment (e.g., Freeman (1986) [23], Perkins (1996) [24]) was also conducted on powdered corals, not only for FE-SEM observations but also for FORC and FMR measurements.

\section{Materials and Methods}

Ishigaki Island is rimmed by coral reefs grown on the bedrock of Ryukyu limestone and Jurassic schist. Large tsunamis transport colonies of Porites and coral boulders from the shallow lagoon and reef edge, and throw them up onto the reef flat and lowlands. This study focuses on four recently ceased coral tsunamigenic boulders collected from Ishigaki Island (Figure 1). Two of the samples were collected from two coral tsunami boulders at Miyara Bay, on the southeastern shoreline of the island. The first, Boulder KK $\left(24^{\circ} 21^{\prime} 15.91^{\prime \prime} \mathrm{N}, 124^{\circ} 12^{\prime} 18.28^{\prime \prime} \mathrm{E}\right.$, named in [25]), is an approximately 40-ton reef boulder near the shoreline (Figure 2a). The second, IST16, was collected from a roughly cylindrical reef boulder $\left(24^{\circ} 21^{\prime} 07.75^{\prime \prime} \mathrm{N}, 124^{\circ} 12^{\prime} 24.31^{\prime \prime} \mathrm{E}\right)$, which has a diameter of $10 \mathrm{~m}$ and a height of $\sim 3 \mathrm{~m}$ (Figure $2 \mathrm{~b}$ ). These two tsunami boulders composed of small coral colonies and fragments (e.g., massive and tabular corals [26]). The natural remanent magnetizations of these boulders were reported in [2]. In addition, two samples were collected from single-colony Porites at Ibaruma $\left(24^{\circ} 31^{\prime} 22.65^{\prime \prime} \mathrm{N}, 124^{\circ} 18^{\prime} 05.98^{\prime \prime} \mathrm{E}\right)$, on the northeastern coast of the island, and named K09 and IB02, respectively (Figure 2c). The top and bottom of the Porites colony were dated from A.D. 1298-1621 and A.D. $1360-1715$, respectively, using ${ }^{14} \mathrm{C}$. The natural remanent magnetizations of these subsamples are represented in the Appendix A (Figures A1 and A2).

To concentrate the magnetic minerals, the following procedure for dissolution of the carbonate matrix was conducted prior to the FE-SEM observations (Boulder KK and K09), FORC measurements (IST16, K09, and IB02), and FMR spectroscopy (IST16, K09, and IB02). Magnetic extraction from the resulting residue was also conducted only for the microscopic observations. Coral skeleton specimens were subsampled using a nonmagnetic diamond saw and crushed with a wooden hammer to prevent contamination of trace metals from the cutting processes, after which the subsamples were sonicated in water and dried at room temperature. Each group of subsamples was then additionally ground using an agate mortar and pestle. The powdered coral skeleton was added to a $500 \mathrm{~mL}$ beaker and dissolved in an aqueous acetic acid solution. During the dissolution, the beaker was left for 7-14 days, and the $\mathrm{pH}$ was controlled from 4 to 5.5. For the FE-SEM (JEOL 7001F FE-SEM at the Department of Earth Science, Tohoku University) observations, the remaining skeleton and iron oxide residue were collected using a permanent neodymium $(\mathrm{NdFeB})$ magnet inserted within a test tube and pipette, 
and transferred onto a glass slide after the dissolution. The last residue was dried in an oven for subsequent FMR and FORC measurements.

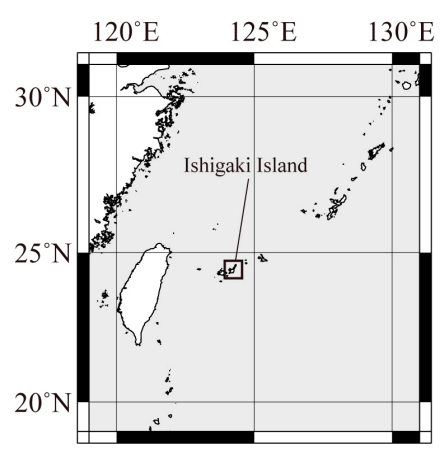

(a)

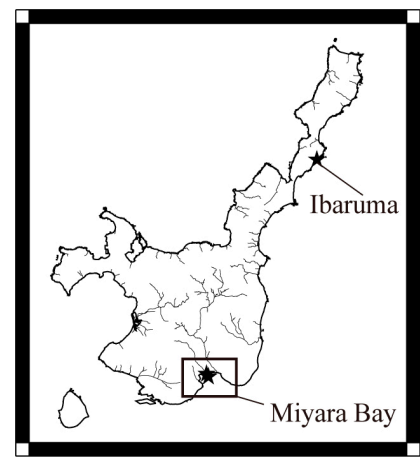

(b)

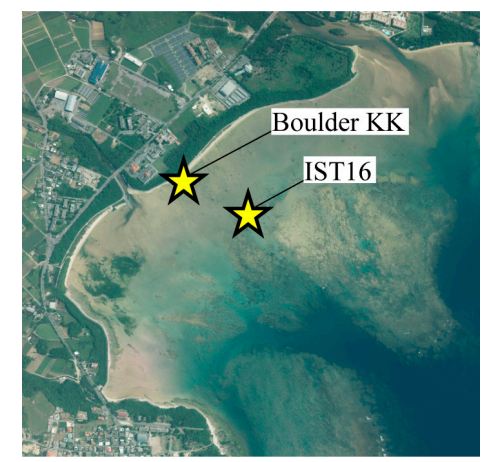

(c)

Figure 1. (a) Map showing the location of Ishigaki Island; and (b) map of Ishigaki Island showing the presence of streams. The black stars indicate the locations of Boulder KK and the cylindrical reef boulder, and the Porites colony on Ibaruma beach. The datasets were downloaded from the National Land Numerical Information download service. (c) Aerial photograph of Miyara Bay area, provided by the Geospatial Information Authority of Japan. The stars indicate the location of Boulder KK, and the cylindrical reef boulder.

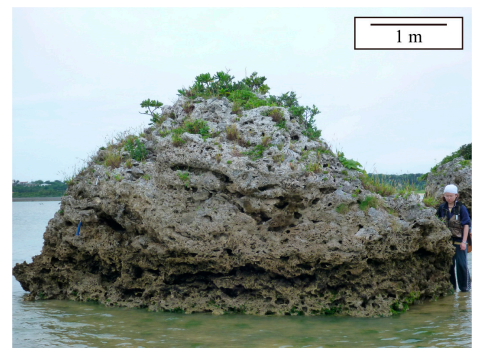

(a)

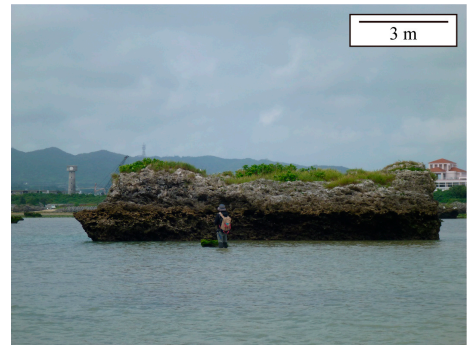

(b)

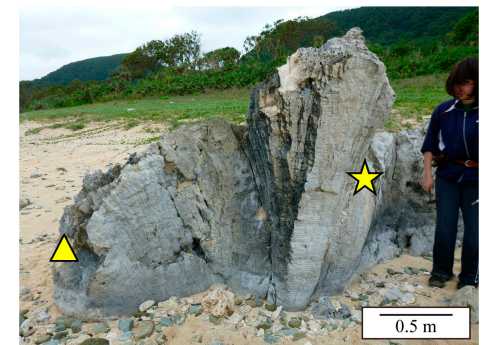

(c)

Figure 2. Sample photographs. (a) Tsunamigenic coral boulder named Boulder KK in [25]; (b) the roughly cylindrical reef boulder with a diameter of $10 \mathrm{~m}$ and a height of $\sim 3 \mathrm{~m}$ (IST16); (c) a Porites colony thrown up on Ibaruma beach. The triangle and star indicate the sampling points of K09 and IB02, respectively.

FMR spectra were obtained using a JEOL JES-RE2X ESR spectrometer at the Department of Chemistry, Tohoku University. In the FMR experiments, a sample is exposed to a change in the direct current (DC) magnetic fields using a fixed microwave. The magnetic moments in a sample absorb microwave energy at an amount that depends on the strength of the external and any internal magnetic fields, and sustain the Larmor precessional motion in an applied field. This absorption occurs when the precession frequency of the magnetization, changed by a static DC magnetic field $B$, corresponds to the perpendicularly applied microwave frequency $v$. The resonance condition can be described as follows:

$$
\hbar v=g \mu_{\mathrm{B}} B,
$$

where $\hbar$ is Plank's constant, $v$ is the frequency of a microwave, $g$ is Landé's splitting factor, $\mu_{\mathrm{B}}$ is Bohr magneton, and $B$ is the applied magnetic field.

According to pioneering studies (e.g., [20,22,27]), some parameters have been defined for an analysis of the FMR spectra, namely, $g_{\text {eff }}, B_{\text {low }}, B_{\text {high }}, \Delta B_{\mathrm{FWHM}}$, and $A$. The effective $g$-factor (Landé factor) is given as follows:

$$
g_{\text {eff }}=\hbar v / \mu_{\mathrm{B}} B_{\text {eff }}
$$


where $B_{\text {eff, }}$ which is the effective magnetic field, is defined as the magnetic field of maximum absorption, or synonymously, the zero crossing field of the derivative spectrum. In addition, $B_{\text {low }}$ and $B_{\text {high }}$ are the positions of half maximum absorption at the low- and high-field ends of the absorption peak, respectively (e.g., $[20,22,27])$, and $\Delta B_{\text {low }}$ and $\Delta B_{\text {high }}$ are given by $\Delta B_{\text {low }}=B_{\text {eff }}-B_{\text {low }}$ and $\Delta B_{\text {high }}=B_{\text {high }}$ $-B_{\text {eff }}$, respectively. Their sum provides the full width at half maximum $\Delta B_{\mathrm{FWHM}}$. The asymmetry ratio $A$ is ascertained through the following equation:

$$
A=\Delta B_{\text {high }} / \Delta B_{\text {low }}
$$

An empirical discrimination parameter that combines $A$ and $\Delta B_{\mathrm{FWHM}}$ is indicated by $\alpha$, and is defined as

$$
\alpha=0.17 A+9.8 \times 10^{-4} \Delta B_{\mathrm{FWHM}}
$$

in [22].

For each measurement, $100-150 \mathrm{mg}$ of air-dried coral powder sample was loaded into glass tubes and exposed to microwaves at a frequency of $\sim 9.4 \mathrm{GHz}$ (X-band) with power of $1 \mathrm{~mW}$. The range of the applied magnetic field was from zero to $800 \mathrm{mT}$. FORC measurement for Boulder KK was conducted using a vibrating sample magnetometer (VSM) (Model 29/3902, Princeton Measurements) at the Japan Agency for Marine-Earth Science and Technology (JAMSTEC) on dry chip subsample. FORC diagram for Boulder KK was obtained by stacking 10 measured FORC diagrams because of weak magnetization. The other FORC measurements were conducted using an alternating gradient magnetometer (AGM) (MicroMag 2900 series AGM, PMC) at the National Institute of Advanced Industrial Science and Technology (AIST) on powdered subsamples (See Table 1 for sample mass and magnetic concentration for FMR and FORC measurements). FORCinel v.3.06 software [28] was used for the data processing. Key parameters for FORCinel calculations (see [29] for details) were: $\mathrm{s}_{\mathrm{c}, 0}=3$, $\mathrm{s}_{\mathrm{c}, 1}=5, \mathrm{~s}_{\mathrm{b}, 0}=3, \mathrm{~s}_{\mathrm{b}, 1}=5$ and $\lambda=0.1$.

Table 1. Summary of sample mass, magnetic concentration, and magnetite contents for FMR and FORC measurements.

\begin{tabular}{cccccc}
\hline Sample Name & $\begin{array}{c}\text { FMR Sample } \\
\text { Mass (mg) }\end{array}$ & $\begin{array}{c}\text { FORC Sample } \\
\text { Mass (mg) }\end{array}$ & $\begin{array}{c}\text { Magnetic } \\
\text { Concentration }\end{array}$ & $\begin{array}{c}\text { Saturation } \\
\text { Magnetization (Am } \mathbf{2} / \mathbf{k g})\end{array}$ & $\begin{array}{c}\text { Magnetite } \\
\text { Contents (wt \%) }\end{array}$ \\
\hline Boulder KK & - & - & No & - & - \\
IST 16 & 107.6 & 10.6 & Yes & $1.3 \times 10^{-2}$ & 1.4 \\
K09 & 153.7 & 7.0 & Yes & $7.4 \times 10^{-2}$ & 8.1 \\
IB02 & 113.3 & 9.2 & Yes & $1.1 \times 10^{-2}$ & 1.1 \\
\hline
\end{tabular}

FE-SEM observations were conducted on two subsamples (Boulder KK and K09). The samples were prepared for SEM observation by allowing approximately $80 \mu \mathrm{L}$ of the suspension of the dissolved coral skeleton residue to dry on a glass slide with a carbon coating. Energy dispersive spectroscopy (EDS) was conducted using an x-act (Oxford Instruments, Abingdon, Oxfordshire, UK) for an elemental analysis.

\section{Results}

Most of the FMR derivative spectra of the coral skeleton samples, with the exception of IB02, indicate multiple derivative maxima and extended low-field absorption, with $A$ between 0.56 and 0.95 , $g_{\text {eff }}$ between 2.06 and 2.11, and $\Delta B_{\mathrm{FWHM}}$ between 111 and $163 \mathrm{mT}$ (Figure 3 and Table 2). Following the criteria used in $[20,22]\left(A<1, g_{\text {eff }}<2.12\right.$, and $\left.\alpha<0.3\right)$, these features are all consistent with the unusual feature of intact biogenic magnetite chains and magnetosome-bearing carbonates, although these samples show FMR spectra broadening at low fields. This broadening is due to inclusions of an isotropic magnetite component [10]. The FMR spectrum for IB02 from the Porites colony shows complex characteristics, particularly at low fields (Figure 3g). The FMR parameters for IB02 are as follows: $g_{\text {eff }}=3.79, \Delta B_{\mathrm{FWHM}}=237.8 \mathrm{mT}, A=1.45>1$, and $\alpha=0.48>0.3$. The spectrum formation and 
parameters resemble those of the FMR spectrum of continental margin marine sediment samples from core MD01-2421, off the shore of central Japan, in the northwest Pacific [10].

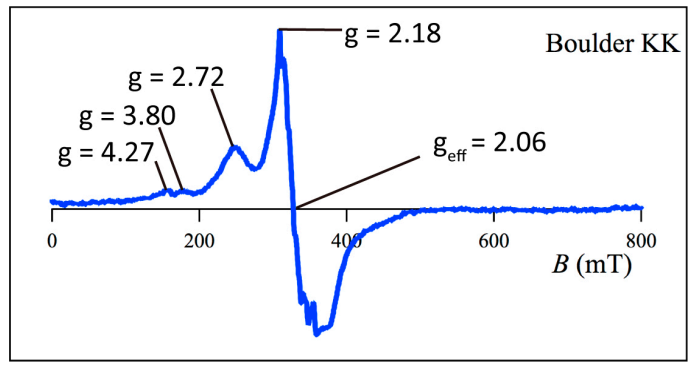

(a)

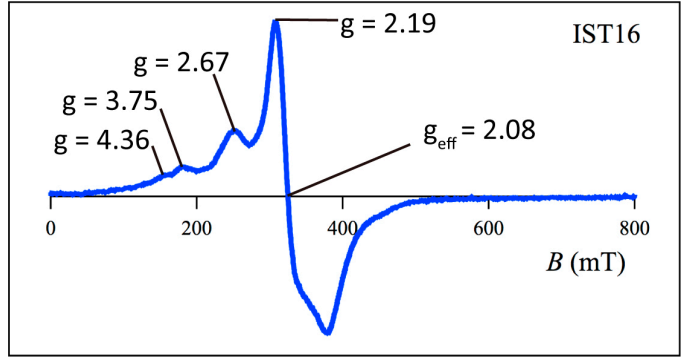

(c)

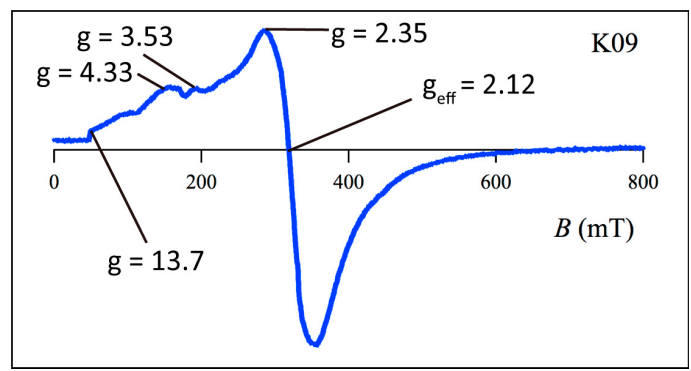

(e)

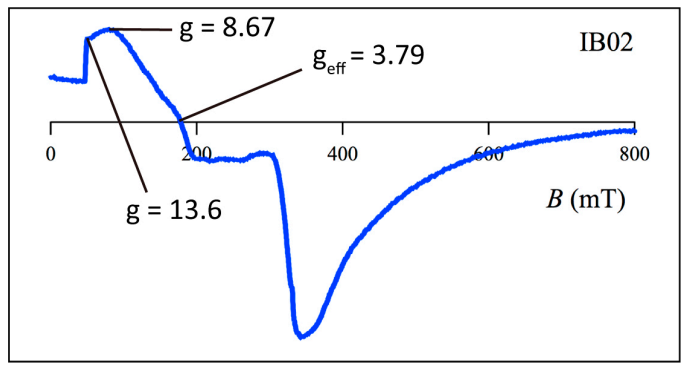

$(\mathrm{g})$

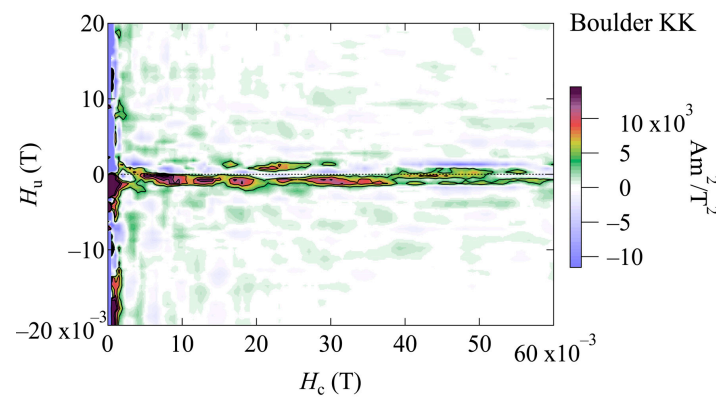

(b)

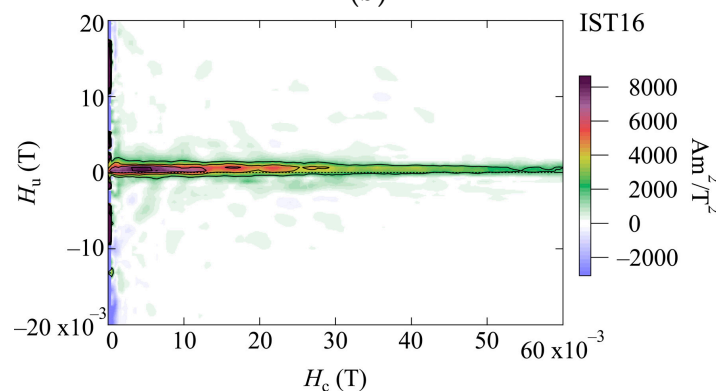

(d)

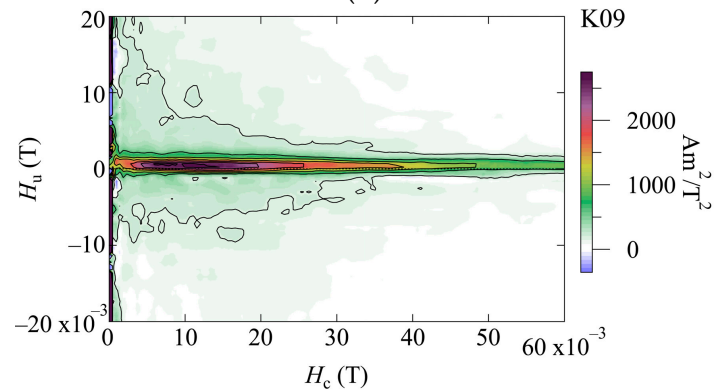

$(\mathbf{f})$

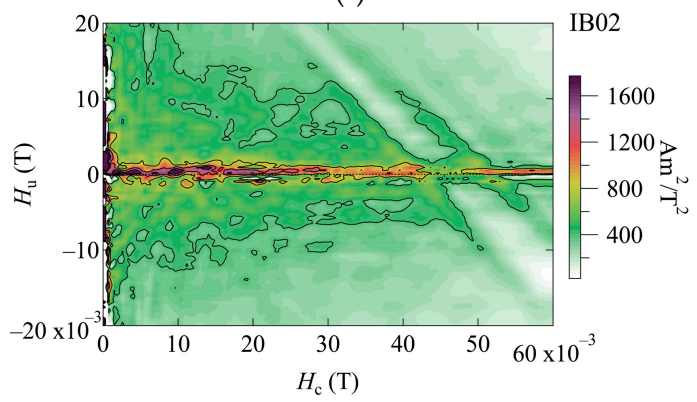

(h)

Figure 3. FMR derivative spectra and FORC diagrams of coral boulders on Ishigaki Island; $(\mathbf{a}, \mathbf{b})$ Boulder KK; (c,d) IST 16; (e,f) K09; and (g,h) IB02.

Table 2. Summary of FMR data and parameters from four measured samples.

\begin{tabular}{cccccccccc}
\hline Samples & $\boldsymbol{B}_{\text {eff }}(\mathbf{m T})$ & $\boldsymbol{g}_{\text {eff }}$ & $\boldsymbol{B}_{\text {low }}(\mathbf{m T})$ & $\boldsymbol{B}_{\text {high }}(\mathbf{m T})$ & $\boldsymbol{\Delta} \boldsymbol{B}_{\text {low }}(\mathbf{m T})$ & $\boldsymbol{\Delta} \boldsymbol{B}_{\text {high }}(\mathbf{m T})$ & $\boldsymbol{\Delta} \boldsymbol{B}_{\text {FWHM }}(\mathbf{m T})$ & $\boldsymbol{A}$ & $\boldsymbol{\alpha}$ \\
\hline Boulder KK & 327.2 & 2.06 & 266.4 & 378.0 & 60.8 & 50.8 & 111.6 & 0.84 & 0.25 \\
Cylindrical boulder (IST16) & 324.7 & 2.08 & 267.8 & 378.8 & 56.8 & 54.1 & 111.0 & 0.95 & 0.27 \\
Porites colony (K09) & 318.6 & 2.11 & 220.6 & 373.7 & 98.1 & 55.1 & 153.2 & 0.56 & 0.25 \\
Porites colony (IB02) & 177.8 & 3.79 & 80.7 & 318.4 & 97.1 & 140.7 & 237.8 & 1.45 & 0.48 \\
\hline
\end{tabular}

Some of our FORC diagrams of the coralline boulders (Boulder KK and IST16) show a dominant central ridge feature with negligible vertical spread (Figure $3 b, d$ ). The results from one of the Porites 
colony samples (K09) show a central ridge feature with a vertical spread (Figure 3f), which indicates the existence of coarser-grained detrital component particles [12,30,31]. These narrow ridges have a peak within an $H_{\mathrm{c}}$ range of $\sim 0-20 \mathrm{mT}$, which is slightly different from the typical range for the coercivity of SD magnetite, at 20-30 mT [14]. This is likely due to the contribution of collapsed magnetosome chains, which will depress the peak coercivity [10]. As discussed in Ludwig et al. (2013) [16], this can be due to an admixture of isolated SD or PSD magnetite particles either of authigenic/pedogenic origin, or in the form of inclusions in silicates of terrigenous origin. Therefore, FORC diagrams indicate that the magnetization of these coral skeletons is mainly carried out through intact magnetosomes and mixtures of grains from collapsed magnetosomes, pseudo-single domain grains, and multi-domain grains such as magnetite grain and magnetic inclusions in silicate, which have terrigenous origin. For the Porites colony sample IB02 (Figure 3h), the diagram shows a FORC distribution located at $H_{\mathrm{u}}$, $H_{\mathrm{C}}=0$.

FE-SEM observations of Boulder KK and K09 indicate the existence of rectangular-shaped iron oxide grains in the coral skeletons (Figure 4a). The sizes of the grains are around $100 \mathrm{~nm}$, with most of the grains composing magnetosomes having grain sizes of between $\sim 40$ and $\sim 150 \mathrm{~nm}$ [32]. The existence of a very short chain of iron oxide grains was also observed in K09 (Figure 4b), suggesting the origin of biogenic magnetite. On the other hand, some iron oxides are observed that represent neither rectangular-shaped morphology nor a chain-like structure (Figure $4 \mathrm{c}, \mathrm{d}$ ). Therefore, the results of FE-SEM observations suggest that the magnetic carriers of coral skeletons on Ishigaki Island are composed of biogenic fine-grained iron oxides that have different (e.g., detrital) origin.

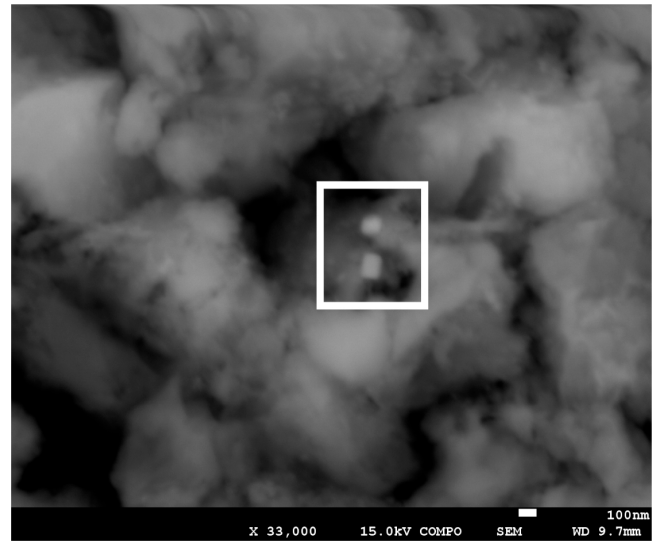

(a)

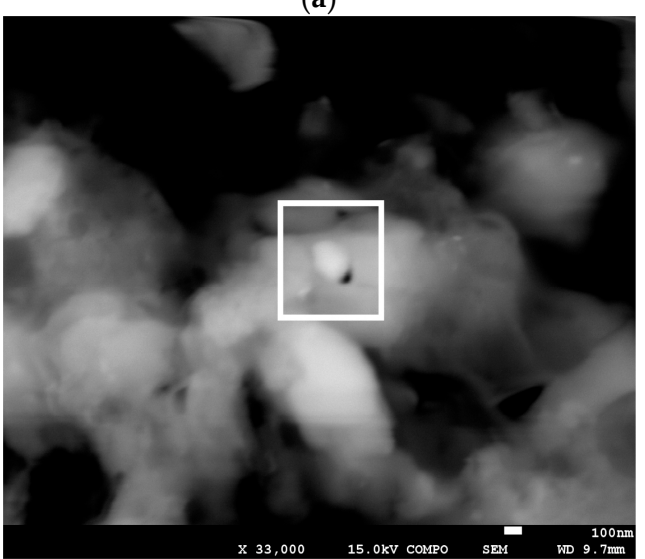

(c)

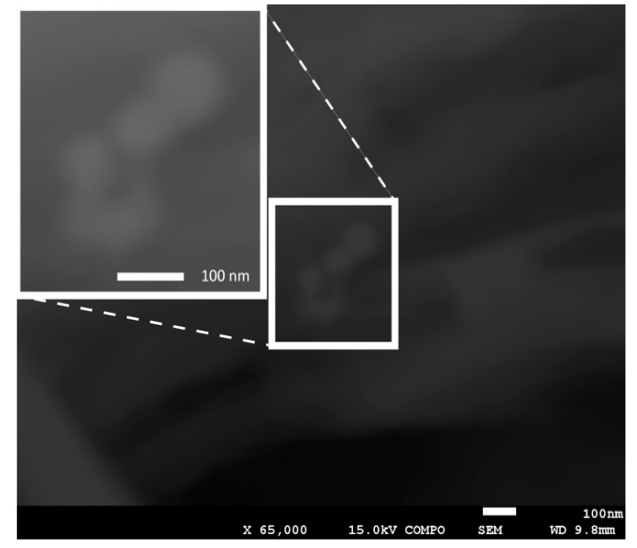

(b)

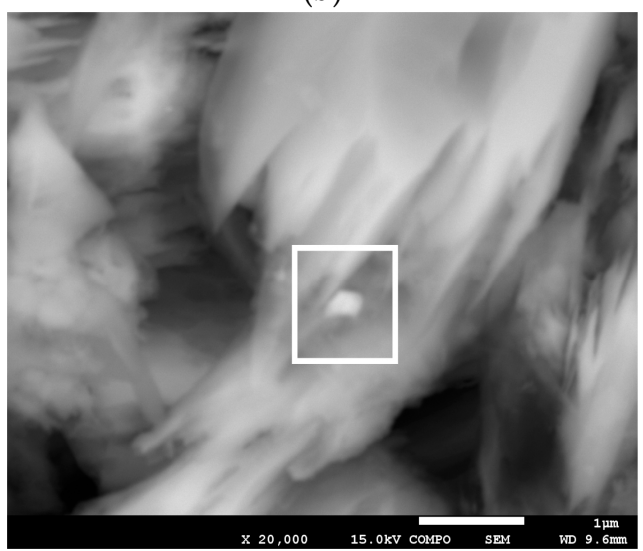

(d)

Figure 4. (a) SEM image of iron oxides in Boulder KK showing a similar shape and size as those of biogenic magnetite. (b) SEM image of iron oxide in K09 from Porites colony aligned in a chain-like structure. The inlet shows a larger and brighter image of the iron oxide grains. (c,d) SEM images of iron oxides that represent a different shape from biogenic magnetite in Boulder KK and K09, respectively. 


\section{Discussion}

FORC diagrams for Boulder KK and the cylindrical reef boulder (IST16) have a narrow ridge FORC distribution along the $H_{\mathrm{c}}$ axis with a lack of vertical spread (Figure 3a,c), which is called a central ridge feature, e.g., [13]. FMR derivative spectra for these coral boulders contain a low-field secondary peak, and the FMR parameters fall within the $g_{\text {eff }}<2.12, A<1$, and $\alpha<0.3$ regions (Figure 3a,c and Table 2). These signatures are all consistent with the presence of intact magnetosome chains, as based on $[13,20,22]$. Therefore, we propose that magnetic carriers in two coral boulders in Miyara Bay are composed mainly of biogenic magnetite chains.

The FORC diagrams and FMR spectra showed distinct features for the K09 and IB02 subsamples from the Porites colony at Ibaruma beach. For K09, the FMR spectrum contains extended low-field absorption lines similar to a near-edge absorption, with the FMR parameters satisfying the criteria of $g_{\text {eff }}<2.12, A<1$, and $\alpha<0.3$ (Figure 3e and Table 2). Magnetostatic interactions within concentrated magnetic particle assemblages may cause the FMR spectra broadening at low fields. To clarify this, nominal magnetite contents are calculated comparing saturation magnetization of samples with one for magnetite of $92 \mathrm{Am}^{2} / \mathrm{kg}$ [33] (Table 1). The values range from $1 \sim 8 \mathrm{wt} \%$, suggesting that most magnetic particles were originally attached to non-carbonate constituents and remained in-place during the extraction procedure. Therefore, the extraction procedure remains some chains of magnetosome.

The FORC diagram shows a central ridge feature with a vertical spread and lower coercivity (Figure 3f). According to [31], these traits indicate the presence of both magnetosome and coarser-grained detrital components. It is also supported by FE-SEM observations, which indicate the presence of iron oxides from biogenic and different origin (Figure $4 b, d$ ). For another subsample, IB02, the FORC diagram shows weak central ridge, vertical spread feature, and a FORC distribution around the origin of the diagram (Figure $3 \mathrm{~h}$ ). The latter may suggest the presence of magnetic grains at or just below the superparamagnetic threshold volume [12]. The FMR spectrum shows different forms and parameters from the magnetosome bearing samples, which resemble those of a continental margin marine sediment sample from off the shore of central Japan, as measured in [10] (Figure 3g). These traits were interpreted in [10] as possible contributions from mixtures of the domain states and magnetic minerals, which have a detrital origin. Our results indicate that the main magnetic carriers of the Porites colony are from both biogenic and detrital fine-grained magnetite, the balance of which might vary depending on the part of the coral skeleton considered. FORC and FMR measurements, and petrologic observations using FE-SEM, were conducted to characterize the magnetic mineral assemblages of coral boulders on Ishigaki Island. Combined analyses of a FORC diagram and FMR spectroscopy confirmed the presence of magnetosomes in the coralline boulders from Miyara Bay. They also indicated that the main magnetic carriers of the Porites colony on the Ibaruma coastline are both magnetosomes and other magnetic minerals, the balance of which might vary dramatically from one part of the Porites skeleton to another. The coral skeletons in Ishigaki Island have the potential to provide a role as a new paleomagnetic recorder if some attention is paid to their origin of magnetic remanence.

Author Contributions: Y.K., N.N. and T.S. prepared the coral skeleton samples, conducted the measurements, analyzed the data, and discussed the results for each sample. T.O. prepared sample tubes for FMR measurements, analyzed the data, and discussed the results for FMR measurements. H.O. provided lab equipment (AGM and superconducting rock magnetometer). Y.K. and N.N. prepared the original draft. T.S., T.O. and H.O. reviewed and edited the manuscript.

Funding: This study was supported by the Japan Society for the Promotion of Science Grant-in-Aid for Scientific Research (B) (15H 02986), and the Institute for International Advanced Research and Education (Tohoku University, Japan).

Acknowledgments: We are grateful to Associate Prof. Kazuhisa Goto of the International Research Institute of Disaster Science, Tohoku University for his valuable comments on tsunami boulders and sample correction. Deep appreciation is expressed to Dr. Yoichi Usui of Japan Agency of Marine-Earth Science and Technology for providing lab equipment (VSM) and his helpful advice regarding the FORC measurements. We are indebted to Prof. Tsutomu Sekine of the Department of Chemistry, Graduate School of Science, Tohoku University for his helpful advice with the FMR measurements and his valuable comments regarding the present manuscript. 
Conflicts of Interest: The authors declare no conflicts of interest.

\section{Appendix}

K09B_1(THD)

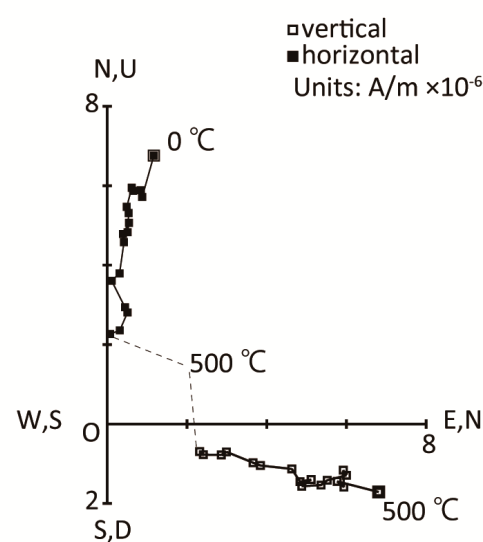

(a)

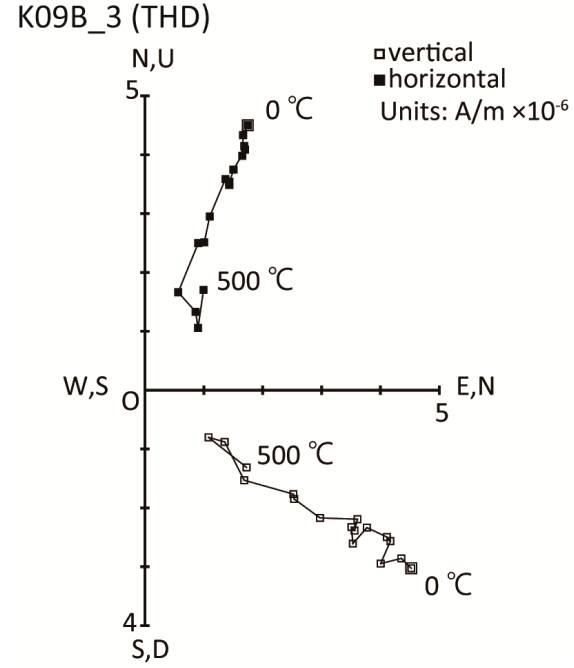

(b)

Figure A1. Vector plots for successive thermal demagnetization steps for 1-inch core samples from K09 (Porites colony): (a) K09B_1; (b) K09B_3. U—up; D—down. All measurements were conducted using a conventional spinner magnetometer (Aspin; Natsuhara Giken Co. Ltd., Osaka, Japan) with a sensitivity of $5 \times 10^{-9} \mathrm{~A} / \mathrm{m}$.

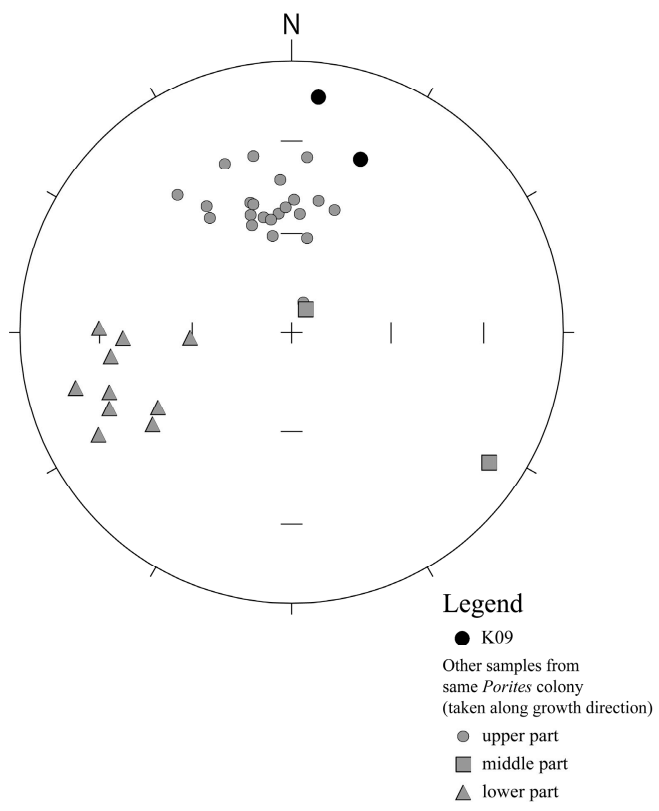

Figure A2. Stereographic projection diagram for characteristic remanent magnetization (ChRM) direction of subsamples from Porites colony at Ibaruma. Directions of ChRM are calculated by PCR method [34] using Puffinplot software [35]. Black circles indicate K09 subsamples (vector plots are shown as Figure A1). It is also shown ChRM results from other subsamples continuously taken along the growth direction of Porites colony (NRM was measured using superconducting rock magnetometer in AIST). Gray circles, squares, and triangles indicate upper part, middle part, lower part of growth direction, respectively. Results of the upper part cluster around the north and those of the lower part cluster around the west direction. This figure is generated using PMAGTOOL [36]. 


\section{References}

1. Mitsuguchi, T.; Matsumoto, E.; Uchida, T. Mg/Ca and Sr/Ca ratios of Porites coral skeleton: Evaluation of the effect of skeletal growth rate. Coral Reefs 2003, 22, 381-388. [CrossRef]

2. Sato, T.; Nakamura, N.; Goto, K.; Kumagai, Y.; Nagahama, H.; Minoura, K. Paleomagnetism reveals the emplacement age of tsunamigenic coral boulders on Ishigaki Island, Japan. Geology 2014, 42, 603-606. [CrossRef]

3. Tauxe, L. Sedimentary records of relative paleointensity of the geomagnetic field: Theory and practice. Rev. Geophys. 1993, 31, 319-354. [CrossRef]

4. McNeill, D.F.; Ginsburg, R.N.; Chang, S.R.; Kirschvink, J.L. Magnetostratigraphic dating of shallow-water carbonates from San Salvador, Bahamas. Geology 1988, 16, 8-12. [CrossRef]

5. Ménabréaz, L.; Thouveny, N.; Camoin, G.; Lund, S.P. Paleomagnetic record of Tahiti (French Polynesia): A contribution to the chronology of the deposits. Earth Planet. Sci. Lett. 2010, 294, 58-68. [CrossRef]

6. Roberts, A.P.; Florindo, F.; Villa, G.; Chang, L.; Jovane, L.; Bohaty, S.M.; Larrasoaña, J.C.; Heslop, D.; Fitz Gerald, J.D. Magnetotactic biogenic abundance in pelagic marine environments is limited by organic carbon flux and availability of dissolved iron. Earth Planet. Sci. Lett. 2011, 310, 441-452. [CrossRef]

7. Yamazaki, T.; Shimono, T. Abundant biogenic magnetite occurrence in oxic red clay. Geology 2013, 41, 1191-1194. [CrossRef]

8. Sakai, S.; Jige, M. Characterization of magnetic particles and magnetostratigraphic dating of shallow-water carbonates in the Ryukyu Islands, northwestern Pacific. Isl. Arc 2006, 15, 468-475. [CrossRef]

9. Li, J.; Wu, W.; Liu, Q.; Pan, Y. Magnetic anisotropy, magnetostatic interactions and identification of magnetofossils. Geochem. Geophys. Geosys. 2012, 13, Q10Z51. [CrossRef]

10. Chang, L.; Roberts, A.P.; Winklhofer, M.; Heslop, D.; Dekkers, M.J.; Krijgsman, W.; Fitz Gerald, J.D.; Smith, P. Magnetic detection and characterization of biogenic magnetic minerals: A comparison of ferromagnetic resonance and first-order reversal curve diagrams. J. Geophys. Res. 2014, 119, 6136-6158. [CrossRef]

11. Pike, C.R.; Roberts, A.P.; Verosub, K.L. Characterizing interactions in fine magnetic particle systems using first order reversal curves. J. Appl. Phys. 1999, 85, 6660-6667. [CrossRef]

12. Roberts, A.P.; Pike, C.R.; Verosub, K.L. First-order reversal curve diagrams: A new tool for characterizing the magnetic properties of natural samples. J. Geophys. Res. 2000, 105, 28461-28475. [CrossRef]

13. Egli, R.; Chen, A.P.; Winklhofer, M.; Kodama, K.P.; Horng, C.S. Detection of noninteracting single domain particles using first-order reversal curve diagrams. Geochem. Geophys. Geosyst. 2010, 11, Q01Z11. [CrossRef]

14. Yamazaki, T. Magnetostatic interactions in deep-sea sediments inferred from first-order reversal curve diagrams: Implications for relative paleointensity normalization. Geochem. Geophys. Geosyst. 2008, 9, Q02005. [CrossRef]

15. Yamazaki, T. Paleoposition of the Intertropical Convergence Zone in the eastern Pacific inferred from glacial-interglacial changes in terrigenous and biogenic magnetic mineral fractions. Geology 2012, 40, 151-154. [CrossRef]

16. Ludwig, P.; Egli, R.; Bishop, S.; Chernenko, V.; Frederichs, T.; Rugel, G.; Merchel, S.; Orgeira, M.J. Characterization of primary and secondary magnetite in marine sediment by combining chemical and magnetic unmixing techniques. Glob. Planet. Chang. 2013, 110, 321-339. [CrossRef]

17. Moskovitz, B.M.; Frankel, R.B.; Bazylinski, D.A. Rock magnetic criteria for the detection of biogenic magnetite. Earth Planet. Sci. Lett. 1993, 120, 283-300. [CrossRef]

18. Penninga, I.; de Waard, H.; Moskowitz, B.M.; Bazylinski, D.A.; Frankel, R.B. Remanence measurements on individual magnetotactic bacteria using a pulsed magnetic field. J. Magn. Magn. Mater. 1995, 149, 279-286. [CrossRef]

19. Dunin-Borkowski, R.E.; McCartney, M.R.; Frankel, R.B.; Bazylinski, D.A.; Posfai, M.; Buseck, P.R. Magnetic microstructure of magnetotactic bacteria by electron holography. Science 1998, 282, 1868-1870. [CrossRef] [PubMed]

20. Weiss, B.P.; Kim, S.S.; Kirschvink, J.L.; Kopp, R.E.; Sankaran, M.; Kobayashi, A.; Komeili, A. Ferromagnetic resonance and low-temperature magnetic tests for biogenic magnetite. Earth Planet. Sci. Lett. 2004, 224, 73-89. [CrossRef]

21. Charilaou, M.; Winklhofer, M.; Gehring, A. Simulation of ferromagnetic resonance spectra of linear chains of magnetite nanocrystals. J. Appl. Phys. 2011, 109, 093903. [CrossRef] 
22. Kopp, R.E.; Weiss, B.P.; Maloof, A.C.; Vali, H.; Nash, C.Z.; Kirschvink, J.L. Chains, clumps, and strings: Magnetofossil taphonomy with ferromagnetic resonance spectroscopy. Earth Planet. Sci. Lett. 2006, 247, 10-25. [CrossRef]

23. Freeman, R. Magnetic mineralogy of pelagic limestones. Geophys. J. Int. 1986, 85, 433-452. [CrossRef]

24. Perkins, A.M. Observations under electron microscopy of magnetic minerals extracted from speleothems. Earth Planet. Sci. Lett. 1996, 139, 281-289. [CrossRef]

25. Goto, K.; Shinozaki, T.; Minoura, K.; Okada, K.; Sugawara, D.; Imamura, F. Distribution of boulders at Miyara bay of Ishigaki Island, Japan: A flow characteristic indicator of tsunami and storm waves. Isl. Arc 2010, 19, 412-426. [CrossRef]

26. Kato, Y.; Kimura, M. Age and origin of so-called "Tsunami-ishi", Ishigaki Island, Okinawa Prefecture. J. Geol. Soc. Jpn. 1983, 89, 471-474. [CrossRef]

27. Kopp, R.E.; Nash, C.Z.; Kobayashi, A.; Weiss, B.P.; Bazylinski, D.A.; Kirschvink, J.L. Ferromagnetic resonance spectroscopy for assessment of magnetic anisotropy and magnetostatic interactions: A case study of mutant magnetotactic bacteria. J. Geophys. Res. 2006, 111. [CrossRef]

28. Harrison, R.J.; Feinberg, J.M. FORCinel: An improved algorithm for calculating first-order reversal curve distributions using locally weighted regression smoothing. Geochem. Geophys. Geosyst. 2008, 9, Q05016. [CrossRef]

29. Egli, R. VARIFORC: An optimized protocol for calculating non-regular first-order reversal curve (FORC) diagrams. Glob. Planet. Chang. 2013, 110, 302-320. [CrossRef]

30. Carvallo, C.; Muxworthy, A.R.; Dunlop, D.J. First-order reversal curve (FORC) diagrams of magnetic mixtures: Micromagnetic models and measurements. Phys. Earth Planet. Inter. 2006, 154, 308-322. [CrossRef]

31. Heslop, D.; Roberts, A.P.; Chang, L.; Davies, M.; Abrajevitch, A.; De Deckker, P. Quantifying magnetite magnetofossil contributions to sedimentary magnetizations. Earth Planet. Sci. Lett. 2013, 382, 58-65. [CrossRef]

32. Kopp, R.E.; Kirschvink, J.L. The identification and biogeochemical interpretation of fossil magnetotactic bacteria. Earth Sci. Rev. 2008, 86, 42-61. [CrossRef]

33. Thompson, R.; Oldfield, F. Environmental Magnetism, 1st ed.; Allen and Unwin Ltd.: London, UK, 1986; p. 23, Print ISBN 978-94-011-8038-2, Online ISBN 978-94-011-8636-8.

34. Kirschvink, J.L. The least-squares line and plane and the analysis of palaeomagnetic data. Geophys. J. R. Astron. Soc. 1980, 62, 699-718. [CrossRef]

35. Lurcock, P.C.; Wilson, G.S. PuffinPlot: A versatile, user-friendly program for paleomagnetic analysis. Geochem. Geophys. Geosyst. 2012, 13. [CrossRef]

36. PMAGTOOL. Available online: https://www.lancaster.ac.uk/staff/hounslow/resources/software/ pmagtool.htm (accessed on 26 October 2018). 